\title{
Çocuklarda Kırım-Kongo Kanamalı Ateşinde Ribavirinin Laboratuvar Testi ve Şiddet Skoru Üzerindeki Etkinliğinin Değerlendirilmesi
}

\section{Evaluation of Efficacy of Ribavirin on Laboratory Test and Severity Score in Crimean-Congo Hemorrhagic Fever in Children}

\author{
Erhan KARAASLAN ${ }^{1}\left(\right.$ ID), Şirin ÇETiN ${ }^{2}$ (ID) \\ ${ }^{1}$ Gaziosmanpaşa Üniversitesi Tıp Fakültesi, Çocuk Sağlığı ve Hastalıkları Anabilim Dalı, Tokat. \\ ${ }^{1}$ Gaziosmanpasa University Faculty of Medicine, Department of Pediatrics, Tokat, Turkey. \\ ${ }^{2}$ Gaziosmanpaşa Üniversitesi Tıp Fakültesi, Biyoistatistik Anabilim Dalı, Tokat. \\ ${ }^{2}$ Gaziosmanpasa University Faculty of Medicine, Department of Biostatistics, Tokat, Turkey.
}

Makale Atıfı: Karaaslan E, Çetin Ş. Çocuklarda Kırım-Kongo kanamalı ateşinde ribavirinin laboratuvar testi ve şiddet skoru üzerindeki etkinliğinin değerlendirilmesi. Mikrobiyol Bul 2021;55(2):180-193.

Öz

Kırım-Kongo kanamalı ateşi (KKKA) Tokat ilinde endemiktir. Tüm yaş gruplarında yaygın olarak görülmektedir. Hastanede yatan erişkin hastalarda olgu ölüm oranı \%20-30, çocuk hastalarda ise $\% 0-5$ arasında değişmektedir. Ribavirin kullanımı ve destekleyici önlemler başlıca tedavi yöntemleridir ancak ribavirinin KKKA üzerindeki etkisi tartışmalıdır. Ribavirinin etkinliğini araştıran çalışmaların çoğunda başlangıç ve son laboratuvar değerleri karşılaştııılmıştır. Bu çalışmada, KKKA tanısı alan çocuklarda mevcut tüm klinik ve laboratuvar bulguları değerlendirilerek, oral ribavirin kullanımı sonucu ortaya çıkan etkilerin değerlendirilmesi ve gözden kaçabilecek sonuçların araştııılması amaçlanmıştır. Çalışmada 2012-2020 epidemi dönemlerinde KKKA tanısıyla hastaneye yatırılan ve takip edilen 19 yaş altı 67 hastanın verileri retrospektif olarak incelenmiştir. Epidemiyolojik ve demografik özellikler, klinik ve laboratuvar verileri hasta dosyalarından geriye dönük olarak alınmıştır. Laboratuvar verilerinin tekrarlanan ölçümlerini hesaba katarak ribavirinin etkilerini değerlendirmek amacıyla doğrusal bir karma etki modeli uygulanmıştır. Hastaların 33 (\%49.2)'üne ribavirin verilmiş, 34 (\%50.7)'üne ise verilmemiştir. Çalışmaya alınan hastaların 54 (\%80.6)'ü erkek, 13 (\%19.4)'ü kadındır. Olguların 52 (\%77.6)'sinin kırsal bölgede, 15 (\%22.4)'inin kentsel bölgede yaşanmakta olduğu saptanmıştır. Ribavirin verilmeyen hastalarda ortalama yaş 15.1 (medyan= 15.5, aralık= 8-18) yıl, ribavirin verilen hastalarda ortalama yaş 15.2 (medyan= 15, aralık= 11-18) yıl olarak bulunmuştur. Başvuru sırasında olguların 63 (\%94)'ünde ateş, 60 (\%89.6)'ında halsizlik, 38 (\%56.7)'inde döküntü, 48 (\%71.6)'inde kas ağrısı, 30 (\%44.8)'unda baş ağrısı, 25 (\%37.3)'inde karın ağrısı, 30 (\%44.8)'unda kusma, 21 (\%31.8)'inde ishal, 29 (\%43.3)'unda uyku hali, 29 (\%43.3)'unda mukozalarda kanama, 27 (\%40.3)'sinde peteşi şikayet ve bulguları görülmüştür. Uyku hali ve mukozal kanama oranları ribavirin verilen hastalarda anlamlı olarak daha yüksek bulunmuştur $(p<0.05)$. Kene tutunmasından hastaneye başvuru anına kadar geçen süre ribavirin almayan hastalarda 4.85 (medyan= 4.5 , aralık= 2-9) gün, ribavirin verilenlerde 4.64 (medyan $=5$ aralık= 2-9) gün olarak bulunmuştur. Ribavirin verilmeyen hastaların hastanede kalış süresi ortalama 6.68 (medyan= 7, aralık= 4-10) gün iken, 
ribavirin tedavisi verilenlerde ortalama 7.45 (medyan= 8, aralık=3-13) gün olarak tespit edilmiştir. Karma model sonuçlarına göre, ribavirinin hemoglobini $(\mathrm{Hb})$ düşürdüğünü (\%95 $\mathrm{GA}=-0.12 /-0.02)$, beyaz kan hücresi sayımını (WBC) (\%95 GA= -0.15/-0.02) ve mutlak lenfosit sayısını $(A L C)(\% 95 \mathrm{GA}=-0.12 / 0.05)$ baskıladığını ve alanin aminotransferaz (ALT) (\%95 GA= -9.32/-1.49), laktat dehidrogenaz (LDH) $(\% 95$ $\mathrm{GA}=-25.06 /-2.36)$ ve şiddet puanı indeksini (\%95 $\mathrm{GA}=-0.28 /-0.004)$ düşürdüğü saptanmıştır. Sonuç olarak ribavirin, KKKA'lı çocuklarda $\mathrm{Hb}, \mathrm{WBC}$ ve ALC seviyelerini baskılamış ancak geçen süre ile karaciğer enzimlerini ve şiddet skorunu daha hızlı düşürmüştür.

Anahtar kelimeler: Kırım-Kongo kanamalı ateşi; çocuk; ribavirin; karma model.

\section{ABSTRACT}

Crimean-Congo hemorrhagic fever (CCHF) is endemic in Tokat province. It is observed in all age groups. The case fatality rate varies $20-30 \%$ in hospitalized patients and $0-5 \%$ among children. Ribavirin use and supportive measures are the main treatment modalities, but the effects of ribavirin in CCHF are controversial. Most of the studies investigating the effectiveness of ribavirin are done by comparing the initial and the final laboratory values. The purpose of this study was to evaluate the effects of oral ribavirin use in children with CCHF by using all the clinical and laboratory findings and to investigate the presence of unnoticed results. In the study, the data of 67 patients under 19 years old who were hospitalized and followed up with a diagnosis of CCHF during 2012-2020 epidemic period were retrospectively analyzed. Epidemiological and demographic characteristics, clinical and laboratory data were retrieved from the patient files. We implemented a linear mixed-effects model to assess the effects of the ribavirin, taking into account the repeated measures of the data. Ribavirin was given to $33(49.2 \%)$ of the patients. 54 $(80.6 \%)$ of the patients were male, $13(19.4 \%)$ were female, $52(77.6 \%)$ of the patients were living in rural areas and $15(22.4 \%)$ were living in urban areas. The mean age was 15.1 (median= 15.5, range= 8-18) years in patients who did not receive ribavirin, and 15.2 (median $=15$, range $=11-18$ ) years in ribavirin administered patients. At the time of admission 63 (94\%) of the patients had fever, 60 (89.6\%) had fatigue, $38(56.7 \%)$ had rash, 48 (71.6\%) had myalgia, $30(44.8 \%)$ had headache, $25(37.3 \%)$ had abdominal pain, 30 (44.8\%) had vomiting, 21 (31.8\%) had diarrhea, 29 (43.3\%) had drowsiness, 29 (43.3\%) had bleeding in the mucosa and 27 (40.3\%) had petechiae. Drowsiness and mucosal bleeding rates were significantly higher in patients who received ribavirin $(p<0.05)$. The time from tick bite to hospital admission was 4.85 (median= 4.5, range=2-9) days in patients who did not receive ribavirin, and 4.64 (median= 5, range $=2-9$ ) days in ribavirin administered patients. The mean length of the hospital stay in patients who did not receive ribavirin was 6.68 (median $=7$, range $=4-10$ ) days, while it was 7.45 (median= 8, range= 3-13) days in those treated with ribavirin. Linear-mixed effect test results showed that ribavirin decreased hemoglobin $(\mathrm{Hb})(95 \% \mathrm{GA}=-0.12 /-0.02)$, suppressed white blood cell count $(\mathrm{WBC})(95 \% \mathrm{GA}=-0.15 /-0.02)$ and absolute lymphocyte count $(\mathrm{ALC})(95 \% \mathrm{GA}=-0.12 / 0.05)$, and decreased alanine aminotransferase (ALT) $(95 \% \mathrm{GA}=-9.32 /-1.49)$, lactate dehydrogenase $(\mathrm{LDH})(95 \%$ $\mathrm{GA}=-25.06 /-2.36)$ and severity score index $(95 \% \mathrm{GA}=-0.28 /-0.004)$. As a result, ribavirin suppressed $\mathrm{Hb}, \mathrm{WBC}$ and $\mathrm{ALC}$ levels in children with $\mathrm{CCHF}$, but decreased liver enzymes and severity score much faster in the elapsed time.

Keywords: Crimean-Congo hemorrhagic fever; children; ribavirin; mixed model.

\section{Giriş̧}

Kırım-Kongo kanamalı ateşi virüsü (KKKAV) Bunyaviridae ailesine, Nairovirus cinsine aittir. Insanlarda oldukça patojenik olan kene kaynaklı bir virüstür. Vasküler sızıntıya bağlı ciddi bir hemorajik hastalığa ve erişkinlerde \%30, çocuklarda \%5'e varan ölüm oranıyla çoklu organ yetmezliğine neden olmaktadır ${ }^{1-3}$. Virüsün bulaşı, kene ısırığı veya kontamine kan ve dokulara maruz kalındığında ortaya çıkar ${ }^{3}$. Karaciğer birincil hedef organdır. KKKAV hepatositleri enfekte ederek nekroza ve karaciğer enzimlerinin salınmasına yol açmaktadır ${ }^{4}$. Klinik ve in vitro çalışmalar, mononükleer fagositlerin, lenfositlerin ve endotel hücrelerin de virüsün önemli birer hedefi olduğunu göstermiştir ${ }^{5,6}$. 
KKKA tedavisi destekleyicidir ${ }^{7}$ ancak ribavirinin hastalığın erken evrelerinde etkili olduğu gösterilmiştir ${ }^{8}$. Ribavirin, respiratuvar sinsitiyal virüs, hepatit $C$, hemorajik ateş virüsleri ve influenza $A$ ve $B$ virüsü gibi RNA virüs enfeksiyonlarında in vitro ve in vivo geniş antiviral aktiviteye sahip bir guanozin nükleosit analoğudur ${ }^{9}$. Hayvan deneylerinde, ribavirinin karaciğerde KKKA virüs replikasyonunu baskıladığı ve diğer organlara enfeksiyonun yayılımını engellediği bildirilmiştir ${ }^{4}$. Bununla birlikte, ilacın KKKA'da in vivo etkinliği sonraki yıllarda şüphe uyandırmıştır ${ }^{10}$.

Yapılan pek çok çalışmada RBV'nin KKKA üzerindeki etkileri, hastanede yatış ve taburculuk günlerinin klinik ve laboratuvar bulguları karşılaştırılarak incelenmiştir. Ancak bu yöntemle değişikliklerin yönünün ve ilacın etkisinin tahmin edilmesi eksik yorumlara yol açabilmektedir.

Bu çalışmada, KKKA'lı çocuklarda mevcut tüm klinik ve tekrarlanan laboratuvar ölçümlerinin istatistiksel karma modeli kullanılarak irdelenmesi ve oral ribavirin kullanımının zamana bağlı olarak etkinliğinin araştırılması amaçlanmıştır.

\section{GEREÇ ve YÖNTEM}

Bu çalışma, Gaziosmanpaşa Üniversitesi Tıp Fakültesi Girişimsel Olmayan Klinik Araştırmalar Etik Kurulu onayı ile gerçekleştirildi (Tarih: 31.12.2020 ve Karar No: 20-KAEK-306).

Retrospektif olarak planlanan çalışma, 2012-2020 yılları arasında Gaziosmanpaşa Üniversitesi Tıp Fakültesi Hastanesi Çocuk Kliniği ve Çocuk Yoğun Bakım Ünitesinde yatan toplam 67 hastanın tıbbi kayıtları incelenerek gerçekleştirildi.

Klinik olarak gözlemlenen semptom ve bulguları (örneğin; ateş, kas ağrısı ve kanama), epidemiyolojik risk faktörleri (kene tutunması, kene teması) ve laboratuvar verileri (trombosit sayısı < 150000/ $\mathrm{mm}^{3}$ ve beyaz kan hücresi (WBC) sayımı $<4000 / \mathrm{mm}^{3}$ ) olan hastalar KKKA'ı hasta olarak tanımlandı ve hastaneye yatırılarak izlendi ${ }^{2}$. Yaş, cinsiyet, yerleşim yeri, kene tutunması öyküsü ve zamanı, semptomlar ve fiziksel bulgular ve laboratuvar bulguları hasta dosyalarından elde edildi. Hastaneye kabul ve taburcu olma tarihine kadar geçen sürede 24 saat aralıklarla sabah yapılan laboratuvar testleri çalışmaya dahil edildi. Gün içinde yapılan diğer testler çalışma dışı bırakıldı. Destekleyici tedavi olarak gerektiğinde trombosit süspansiyonunu ve taze donmuş plazma tedavileri verildi. Oral ribavirin, Dünya Sağlık Örgütü (WHO) tarafından önerilen dozda (ilk yükleme dozu olarak $30 \mathrm{mg} / \mathrm{kg}, 4$ gün boyunca 6 saatte bir $15 \mathrm{mg} / \mathrm{kg}$ ve 6 gün boyunca 8 saatte bir $7.5 \mathrm{mg} / \mathrm{kg}$ ) uyguland ${ }^{2}$.

Başvuru günü, KKKA şüphesi olan hastalardan alınan tam kan örnekleri Türkiye Refik Saydam Halk Sağlığı Genel Müdürlüğü Referans Laboratuvarına gönderildi. Çalışmamıza sadece gerçek zamanlı revers transkriptaz polimeraz zincir reaksiyonu (rRT-PCR) pozitif olgular dahil edildi. Ciddiyet puanlaması için Dokuzoğlu ve arkadaşları ${ }^{11}$ tarafından geliştirilen bir puanlama sistemi kullanıldı. 


\section{İstatistiksel Analiz}

Hastaların hastaneye kabul tarihi ve taburcu tarihine kadar geçen sürede 24 saat aralıklarla yapılan laboratuvar tetkikleri retrospektif olarak incelendi. Ribavirinin tekrarlanan günlerdeki laboratuvar testleri ve şiddet skor indeksindeki değişimini tahmin etmek için karışık model analizi kullanıldı.

Literatürde tekrarlanan ölçümlü verilerin analizi genelleştirilmiş lineer model (GLM) ve karma model analizi ile yapılabilir. GLM analizi yalnızca Birleşik Simetri varyans kovaryans yapısını kullanarak analiz yaparken, karma model analizi tüm varyans kovaryans matrislerini kullanarak analiz yapar. Karma model analizi tekrarlanan ölçümlü verilerin modellenmesi için GLM'den daha fazla alternatif sunar ${ }^{12}$.

Bu çalışmada, karma modelleme kullanılmasının nedeni hastaların hastanede kalış süreleri ve buna bağlı olarak da laboratuvar test sayılarının her hasta için farklı olmasıydı. Bu farklılık tekrarlanan laboratuvar ölçümlerinde eksik verilere neden olmaktadır. Bu tip verilerin analizinin biyoistatistikte karma model yardımıyla yapılması önerilmektedir ${ }^{13}$. Karma model, eksik verilerin olması durumunda klinik uygulamalarda çok sık tercih edilen bir analiz yöntemidir. GLM modeli eksik laboratuvar verisi olan hastaları değerlendirme dışı bıraktığı için hastaların birçok laboratuvar bulguları hesaplamaya katılmamaktadır. Hastalardan alınmış bazı laboratuvar verilerinin analize alınmaması istenmeyen bir durumdur. Verilerin tamamının kullanılması için karma model analizini kullanmak gerekmektedir. Karma model analizi, eksik laboratuvar verisi olan hastaların ölçümleri olan tüm günlerdeki laboratuvar verilerinin de analize katılmasına olanak sağlamaktadır ${ }^{12}$.

Bu çalışmada GLM modeli ile analiz yapılmış olsaydı, laboratuvar verilerinin bazıları analize katılamayacak ve hasta başına bazı laboratuvar bulguları hariç tutulduğunda ribavirin ilacının etkilerini açıklamada yanlış yorumlamaya neden olabilecekti. Bu nedenle çalışmamızda eksik laboratuvar verilerini de dikkate alan karma model ile analiz yapıldı.

Ribavirinin etkisini gözlemlemek için hastalarımızın 0-12 gün arasında laboratuvar değerleri ve klinik gözlemleri ölçüldü. Hastaların hastanede kalış süreleri farklı olduğu için tekrarlanan klinik değerler farklı gün sayılarında elde edildi. Çalışmada laboratuvar değerleri bağımlı değişken olarak alınıp model "Y $Y_{\mathrm{ijk}}=\mu+\beta_{i}+\gamma_{k}+(\beta \gamma)_{i k}+\mu_{i j}+\mathrm{e}_{\mathrm{ijk}}$ " şeklinde tanımlandı. $Y_{i j k}$ laboratuvar değerlerini, $\mu$ popülasyon ortalamasını, $\beta_{\mathrm{i}}$ ribavirinin etkisini, $\gamma_{k}$ gün etkisini, $\mu_{i j}$ hastalar arası değişiklikten kaynaklanan hatayı ve hasta içi değişiklikten kaynaklanan hatayı ifade etmektedir.

Bağımlı değişkenin değişim oranının zaman içinde nasıl ve ne yönde etkilendiğini araştırmak için rastgele kesim noktası ("random intercept") eğim modeli kullanıldı. Grup karşılaştırmaları, ki-kare veya Fisher Exact testi ile ve t testi veya Mann-Whitney $U$ testi kullanılarak yapıldı ve $\mathrm{p}<0.05$ istatistiksel olarak anlamlı kabul edildi.

\section{BULGULAR}

2012-2020 yılları salgın döneminde 67 çocuk veya ergen KKKA tanısıyla hastaneye kaldırılmış; bunlardan 33'üne ribavirin tedavisi verilmiştir. Tüm hastalar kene tutunma- 
sı tarif etmiştir. Demografik özellikler ve klinik özellikler Tablo I'de sunulmuştur. Her iki grupta da yaş farkı bulunmamıştır. Ribavirin verilmeyen hastalarda 15.1 (ortanca= 15.5) yıl ve ribavirin verilen hastalarda 15.2 (ortanca= 15) yıl olarak belirlenmiştir. Ribavirin alan hastalarda daha sık görülen uyku hali ve mukozal kanamalar $(p<0.05)$ dışında her iki grubun başvuru sırasında klinik özellikleri birbirine benzer bulunmuştur. Ateş, halsizlik, kas ağrısı ve baş ağrısı her iki grupta da istatistiksel olarak anlamlı olmayan en yaygın semptomlar olarak belirlenmiştir. Kene tutunmasından sonra başvuru süresi, tedavi edilen grupta 4.64 (ortanca= 5.0 ve aralık= 2-9) gün ve tedavi edilmeyen grupta 4.85 (ortanca $=4.5$ ve aralık=2-9) gün olup her iki grupta da istatistiksel olarak fark saptanmamıştır. Hastanede kalış süresi istatistiksel olarak farklı olmayıp tedavi edilmeyen grupta 6.68

\begin{tabular}{|c|c|c|c|c|}
\hline & $\begin{array}{c}\text { Ribavirin } \\
\text { verilmeyenler }\end{array}$ & $\begin{array}{l}\text { Ribavirin } \\
\text { verilenler }\end{array}$ & Toplam & $p$ \\
\hline Cinsiyet (Erkek) & $27(79.4)$ & $27(81.8)$ & $54(80.6)$ & $0.800^{* *}$ \\
\hline Yerleşim (Kırsal) & $26(76.5)$ & $26(78.8)$ & $52(77.6)$ & $0.820^{* *}$ \\
\hline Yaş (YıI) & $15.1(15.5)$ & $15.2(15)$ & & $0.710^{*}$ \\
\hline \multicolumn{5}{|l|}{ Klinik özellikler } \\
\hline Ateş & $30(88.2)$ & $33(100)$ & $63(94.0)$ & $0.060^{* * *}$ \\
\hline Halsizlik & $31(91.2)$ & $29(87.9)$ & $60(89.6)$ & $0.500^{* * *}$ \\
\hline Döküntü & $22(64.7)$ & $16(48.5)$ & $38(56.7)$ & $0.180^{* *}$ \\
\hline Kas ağrısı & $24(70.6)$ & $24(72.7)$ & $48(71.6)$ & $0.840^{* *}$ \\
\hline Baş ağrısı & $12(35.3)$ & $18(54.5)$ & $30(44.8)$ & $0.110^{* *}$ \\
\hline Karın ağrısı & $11(32.4)$ & $14(42.4)$ & $25(37.3)$ & $0.390^{* *}$ \\
\hline Kusma & $13(38.2)$ & $17(51.5)$ & $30(44.8)$ & $0.270^{* *}$ \\
\hline İshal & $8(23.5)$ & $13(40.6)$ & $21(31.8)$ & $0.130^{* *}$ \\
\hline Uyku hali & $9(26.5)$ & $20(60.6)$ & $29(43.3)$ & $0.005^{* *}$ \\
\hline Mukozal kanama & $9(26.5)$ & $20(60.6)$ & $29(43.3)$ & $0.004^{* *}$ \\
\hline Peteşi & $11(32.4)$ & $16(58.5)$ & $27(40.3)$ & $0.170^{* *}$ \\
\hline Hastanede yatış (gün) & $6.68(7)$ & $7.45(8)$ & & $0.120^{*}$ \\
\hline PLT transfüzyonu (ünite) & $1.76(0)$ & $1.88(2)$ & & $0.280^{*}$ \\
\hline TTP transfüzyonu (ünite) & $2.88(0)$ & $2.06(0)$ & & $0.550^{*}$ \\
\hline Başvuru süresi (gün) & $4.85(4.5)$ & $4.64(5)$ & & $0.640^{*}$ \\
\hline \multicolumn{5}{|l|}{ Başvuruda SSI } \\
\hline Hafif (0-3) & $20(58.8)$ & $9(27.3)$ & $29(43.3)$ & $0.030^{* *}$ \\
\hline Orta (4-7) & $10(29.4)$ & $16(48.5)$ & $26(38.8)$ & \\
\hline Ağır (8-12) & $4(11.8)$ & $8(24.2)$ & $12(17.9)$ & \\
\hline \multirow{2}{*}{\multicolumn{5}{|c|}{ SSI: Ciddiyet skor indeksi, PLT: Trombosit süspansiyonu, TTP: Taze donmuş plazma. }} \\
\hline & & & & \\
\hline \multicolumn{5}{|l|}{ **ki-kare testi. } \\
\hline ***Fisher Exact testi. & & & & \\
\hline
\end{tabular}


(ortanca = 7, aralık= 4-10) gün ve tedavi edilen grupta 7.45 (ortanca= 8, aralık= 3-13) gün bulunmuştur. Destekleyici tedavi oranları her iki grupta da benzer olup ribavirin ile tedavi edilen hastalar trombosit süspansiyonu 1.88 (ortanca $=2$, aralık=0-9) ünite ve tedavi edilmeyen hastalar 1.76 (ortanca $=0$, aralık=0-15) ünite trombosit süspansiyonu almıştır. Ağır ve orta şiddette ciddiyet skor indeksi (SSI) olan hastalar ribavirin ile tedavi edilen grupta anlamlı olarak daha yaygın bulunmuştur $(p<0.05)$.

Hastaneye başvuru anında, her iki gruptaki hastaların tamamında lökopeni, trombositopeni ve yüksek aspartat aminotransferaz (AST), alanin aminotransferaz (ALT), laktat dehidrojenaz (LDH), uzamış protrombin zamanı (PT) ve aktive parsiyel tromboplastin zamanı (aPTT) olduğu belirlenmiştir. Hastaneye kabul sırasındaki tüm testler gruplar arasında önemli ölçüde farklılık göstermemiştir. Başvuru sırasında saptanan laboratuvar verileri Tablo II'de sunulmuştur.

Ribavirinin hemoglobin $(\mathrm{Hb})$ değeri üzerindeki etkisini araştırmak için hemoglobin düzeylerindeki değişiklikler kaydedilmiştir (Şekil 1-A). Hb üzerinde ribavirin ile zaman arasında istatistiksel olarak anlamlı etkileşim etkisi olduğu saptanmıştır $(p<0.05)$. Etki güçlü $(-0.07,[0.002])$ ve \%95 GA (-0.12/-0.02) aralığı dar bulunmuştur. Ribavirin, zamanla $\mathrm{Hb}$ seviyesinde önemli bir düşüşe neden olmuştur. Ribavirinin WBC düzeyine ana etkisi anlamlı değilken $(p=0.112)$, zaman ile etkileşim anlamlı $(-0.09$ [0.27], $p=0.008$ ve \%95 GA= -0.15/-0.02) olarak bulunmuştur. ilacın, zamanla WBC düzeylerinde düşmeye yol açtığı gösterilmiştir (Şekil 1-B). Mutlak nötrofil sayısı (ANC) ( $p=0.92$ ve \%95 $\mathrm{GA}=-0.10 / 0.06)$ üzerinde ribavirinin zamana bağlı etkileşim etkisi olmadığı görülmüştür

\begin{tabular}{|c|c|c|c|}
\hline Laboratuvar bulguları & Ribavirin verilmeyenler & Ribavirin verilenler & $\mathrm{p}$ \\
\hline $\mathrm{Hb}$ & $13.6 \pm 1.38$ & $13.6 \pm 1.14$ & $0.950^{*}$ \\
\hline WBC $\left(10^{3} / \mathrm{ml}\right)$ & $2.47(2.24)$ & $2.49(2.2)$ & $0.960^{* *}$ \\
\hline ANC $\left(10^{3} / \mathrm{ml}\right)$ & $1.57(1.05)$ & $1.58(1.36)$ & $0.870^{* *}$ \\
\hline $\operatorname{ALC}\left(10^{3} / \mathrm{ml}\right)$ & $0.65(0.55)$ & $0.61(0.50)$ & $0.680^{* *}$ \\
\hline PLT $\left(10^{3} / \mathrm{ml}\right)$ & $94.8(96.2)$ & $101(96)$ & $0.810^{* *}$ \\
\hline $\operatorname{ALT}(\mathrm{U} / \mathrm{L})$ & $59.6(33.0)$ & $63.7(35)$ & $0.790^{* *}$ \\
\hline AST (U/L) & $116.0(58.7)$ & $132(72.5)$ & $0.590^{* *}$ \\
\hline $\mathrm{LDH}(\mathrm{U} / \mathrm{L})$ & $431(359)$ & $476(406)$ & $0.400^{* *}$ \\
\hline PT (sn) & $14.8(13.8)$ & $15.4(15.1)$ & $0.190^{* *}$ \\
\hline APTT (sn) & $40.1(38.0)$ & $39.3(38.4)$ & $0.830^{* *}$ \\
\hline Fibrinojen (mg/dl) & $222 \pm 67.8$ & $214 \pm 65.0$ & $0.490^{*}$ \\
\hline INR & $1.25(1.12)$ & $1.26(1.17)$ & $0.480^{* *}$ \\
\hline \multicolumn{4}{|c|}{$\begin{array}{l}\text { Hb: Hemoglobin, WBC: Beyaz küre sayısı, ANC: Mutlak nötrofil sayıII, ALC: Mutlak lenfosit sayıII, PLT: Trombosit } \\
\text { sayıIS, ALT: Alanin aminotransferaz, AST: Aspartat aminotransferaz, LDH: Laktat dehidrogenaz, PT: Protrombin zama- } \\
\text { nı, aPTT: Aktifleştirilmiş parsiyel tromboplastin zamanı. }\end{array}$} \\
\hline
\end{tabular}




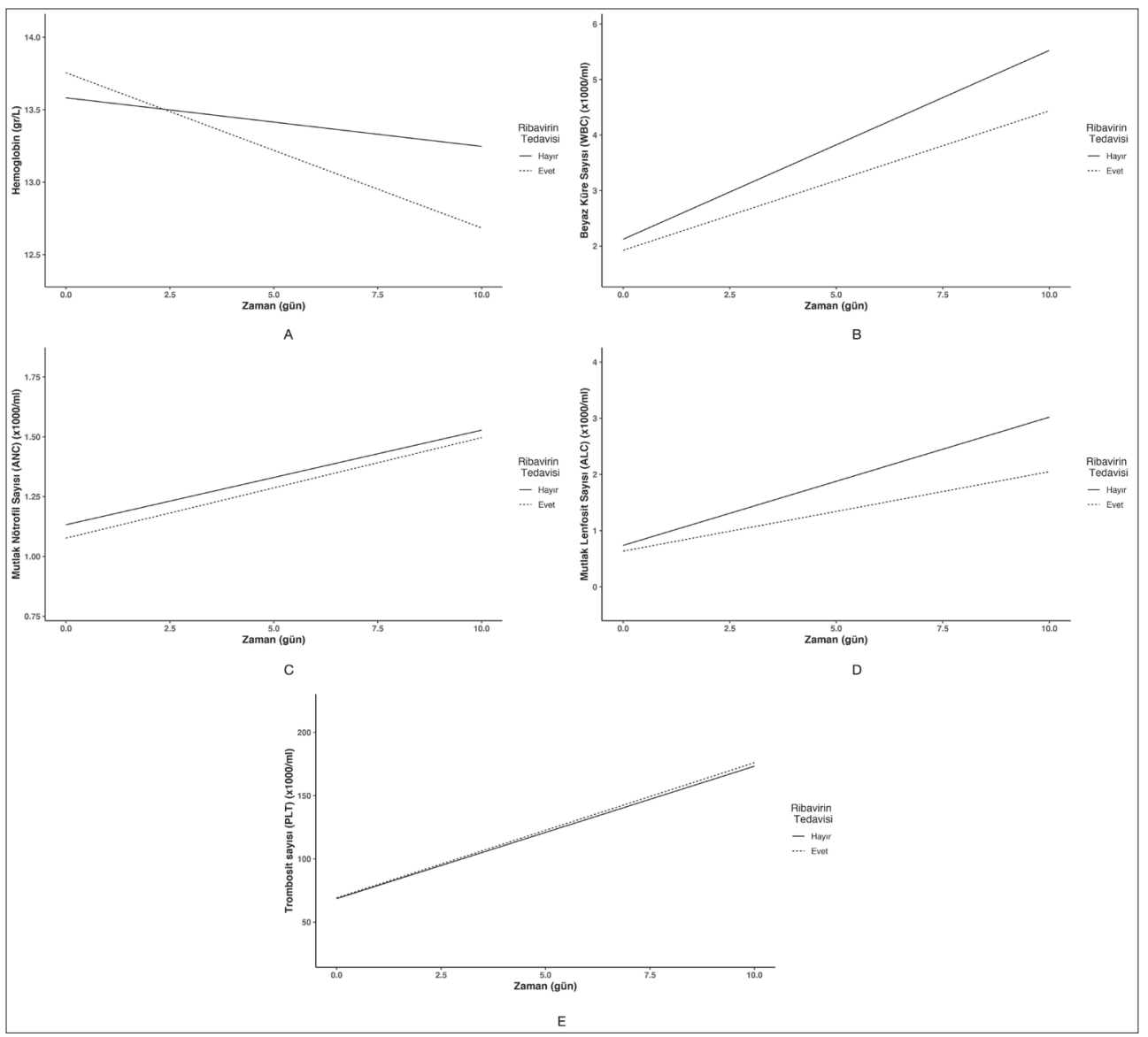

Şekil 1. Kan sayımı değerlerinin ribavirin-zaman etkileşim eğrileri.

(Şekil 1-C). Mutlak lenfosit sayımı (ALC), (-0.09 [0.02], $p<0.001$ ve \%95 GA: -0.12/0.05) üzerinde zaman ve ribavirinin önemli bir etkisi olduğu, ilacın zamanın ilerlemesi ile mutlak lenfosit sayısını baskıladığı anlaşılmıştır (Şekil 1-D). Ribavirinin, trombosit (PLT) sayısı üzerindeki etkisi anlamlı bulunmamıştır $(p=0.89)$. Sonuçlar Tablo III ve Şekil 1'de gösterilmiştir.

Alanin aminotransferaz üzerinde ribavirin ile zaman arasında etkileşim etkisi anlamlı bulunmuştur $(\mathrm{p}<0.05)$. Zaman ile ribavirin etkileşim etki değeri -5.41 (1.99) ,\%95 GA= -9.32/-1.49 olup, ribavirinin KKKA'lı çocuklarda ALT seviyelerinin yükselmesini baskıladığı görülmüştür. Aspartat aminotransferaz üzerindeki ribavirin ile zaman arasındaki etki anlamlı bulunmazken, AST üzerindeki zaman ile etkileşim etki değerinin negatif yönde olduğu (-6.72 [3.81], $\mathrm{p}=0.078, \% 95 \mathrm{GA}=-14.22 /-1.49)$ belirlenmiştir. AST/ALT oranının ribavirin verilen hastalarda zamanla önemli ölçüde etkileşime girdiği görülmüştür $(-0.08$ [0.01], $\mathrm{p}<0.001, \% 95 \mathrm{GA}=-011 /-0.05)$, bu durum ribavirinin AST/ALT oranını daha hızlı 
Tablo III. Kan Sayım Elemanlarının Ribavirin ve Zaman Arasındaki Etkileşimlerinin Doğrusal Karma Model ile Analizi

\begin{tabular}{|c|c|c|c|c|}
\hline & Ortalama etki/SE & $\% 95$ GA & $\mathbf{F}$ & $\mathbf{p}$ \\
\hline \multicolumn{5}{|l|}{$\mathrm{HB}(\mathrm{gr} / \mathrm{dl})$} \\
\hline Ribavirin & $0.17(0.32)$ & $-0.48 / 0.82$ & 0.12 & 0.726 \\
\hline Zaman (gün) & $-0.03(0.02)$ & $-0.07 / 0.004$ & 35.88 & $<0.001$ \\
\hline Ribavirin* zaman & $-0.07(0.02)$ & $-0.12 /-0.02$ & 8.48 & 0.003 \\
\hline \multicolumn{5}{|l|}{ WBC $\left(10^{3} / \mathrm{ml}\right)$} \\
\hline Ribavirin & $-0.20(0.27)$ & $-0.73 / 0.33$ & 2.59 & 0.112 \\
\hline Zaman (gün) & $0.34(0.02)$ & $0.29 / 0.38$ & 298.03 & $<0.001$ \\
\hline Ribavirin* zaman & $-0.09(0.03)$ & $-0.15 /-0.02$ & 6.919 & 0.008 \\
\hline \multicolumn{5}{|l|}{ ANC $\left(10^{3} / \mathrm{ml}\right)$} \\
\hline Ribavirin & $-0.06(0.15)$ & $-0.36 / 0.24$ & 0.058 & 0.809 \\
\hline Zaman (gün) & $0.04(0.02)$ & $0.003 / 0.08$ & 10.88 & $<0.001$ \\
\hline Ribavirin* zaman & $-0.002(0.02)$ & $-0.05 / 0.05$ & 0.009 & 0.921 \\
\hline \multicolumn{5}{|l|}{$\operatorname{ALC}\left(10^{3} / \mathrm{ml}\right)$} \\
\hline Ribavirin & $-0.10(0.16)$ & $-0.42 / 0.22$ & 4.73 & 0.033 \\
\hline Zaman (gün) & $0.22(0.01)$ & $0.20 / 0.25$ & 438.66 & $<0.001$ \\
\hline Ribavirin* zaman & $-0.09(0.02)$ & $-0.12 /-0.05$ & 25.26 & $<0.001$ \\
\hline \multicolumn{5}{|l|}{$\operatorname{PLT}\left(10^{3} / \mathrm{ml}\right)$} \\
\hline Ribavirin & $-0.59(12.03)$ & $-23.43 / 24.62$ & 0.303 & 0.580 \\
\hline Zaman (gün) & $10.46(1.28)$ & $7.93 / 12.99$ & 155.24 & $<0.001$ \\
\hline Ribavirin* zaman & $0.22(1.71)$ & $-3.15 / 3.58$ & 0.016 & 0.890 \\
\hline
\end{tabular}

SE: Standart hata, GA: Güven aralığı, HB: Hemoglobin, WBC: Beyaz küre sayısı, ANC: Mutlak nötrofil sayısı, ALC: Mutlak lenfosit sayısı, PLT: Trombosit sayısı.

düşürdüğünü göstermiştir. LDH'nin ana etkisi pozitif olmasına rağmen, bu durum istatiksel olarak anlamlı bulunmamıştır (100.40 [48.23], $p=0.30 \% 95 \mathrm{GA}=4.07 / 196.74)$ ancak ribavirinin zaman ile etkileşimi LDH değerini negatif yönde etkilemekte olup bu durum istatistiksel olarak anlamlı bulunmuştur (-13.71 [5.76], $p=0.018$ ve \%95 GA= -25.06/2.36). Bu bulgu, ribavirinin $L^{2} H^{\prime} y i$ süre geçtikçe daha hızlı düşürdüğünü düşündürmektedir. Protrombin zamanı (PT) üzerinde, ribavirin ile zaman arasındaki etki anlamlı bulunmamış; PT üzerinde, zaman ile etkileşimin etki değeri negatif yönde izlenmiştir (-0.02 [0.09], $\mathrm{p}=0.850, \% 95 \mathrm{GA}=-0.19 / 0.16$ ). Aktive parsiyel tromboplastin zamanı (aPTT) üzerinde, ribavirin ile zaman arasındaki etki anlamlı bulunmamış, aPTT üzerindeki zaman ile etkileşim etki değeri negatif yönde belirlenmiştir $(-0.19[0.25], p=0.448, \% 95 \mathrm{GA}=-0.70 / 0.31)$. Günlük bazda ciddiyet skor indeksi (SSI) puanlamasına göre klinik özellikler, SSI puanı ile ribavirin kullanımı arasındaki etkileşim anlamlı ve negatif bulunmuş ve bu sonuç ribavirin kullanımının SSI değerini iyileşme yönünde etkilediğini göstermiştir (Tablo IV ve Şekil 2). 
Tablo IV. Karaciğer Enzimleri, Pıhtılaşma Test ve Ciddiyet Skoru Değerlerinin Ribavirin ve Zaman Arasındaki Etkileşimlerinin Doğrusal Karma Model ile Analizi

\begin{tabular}{|c|c|c|c|c|}
\hline & Ortalama etki/SE & $\% 95$ GA & $\mathrm{F}$ & $\mathbf{p}$ \\
\hline \multicolumn{5}{|l|}{$\operatorname{AST}(\mathrm{U} / \mathrm{L})$} \\
\hline Ribavirin & $11.36(26.28)$ & $-41.12 / 63.83$ & 0.41 & 0.520 \\
\hline Zaman (gün) & $-1.99(2.86)$ & $-7.62 / 3.63$ & 9.33 & 0.002 \\
\hline Ribavirin * zaman & $-6.72(3.81)$ & $-14.22 / 0.77$ & 3.10 & 0.078 \\
\hline \multicolumn{5}{|l|}{$\operatorname{ALT}(\mathrm{U} / \mathrm{L})$} \\
\hline Ribavirin & $-0.90(17.36)$ & $-33.78 / 35.58$ & 0.80 & 0.370 \\
\hline Zaman (gün) & $10.44(1.49)$ & $7.50 / 13.38$ & 56.08 & $<0.001$ \\
\hline Ribavirin * zaman & $-5.41(1.99)$ & $-9.32 /-1.49$ & 7.38 & 0.007 \\
\hline \multicolumn{5}{|l|}{ AST/ALT } \\
\hline Ribavirin & $0.46(0.18)$ & $0.11 / 0.82$ & 0.19 & 0.659 \\
\hline Zaman (gün) & $-0.19(0.01)$ & $-0.22 /-0.17$ & 843.53 & $<0.001$ \\
\hline Ribavirin* zaman & $-0.08(0.01)$ & $-0.11 /-0.05$ & 23.25 & $<0.001$ \\
\hline \multicolumn{5}{|l|}{ LDH (U/L) } \\
\hline Ribavirin & $100.40(48.23)$ & $4.07 / 196.74$ & 1.08 & 0.300 \\
\hline Zaman (gün) & $-14.99(4.18)$ & $-23.22 / 6.77$ & 59.38 & $<0.001$ \\
\hline Ribavirin * zaman & $-13.71(5.76)$ & $-25.06 /-2.36$ & 5.64 & 0.018 \\
\hline \multicolumn{5}{|l|}{ ALT/LDH } \\
\hline Ribavirin & $-0.01(0.04)$ & $-0.09 / 0.06$ & 2.02 & 0.159 \\
\hline Zaman (gün) & $0.04(0.003)$ & $-0.03 / 0.04$ & 191.28 & $<0.001$ \\
\hline Ribavirin * zaman & $-0.01(0.004)$ & $-0.02 /-0.004$ & 9.075 & 0.002 \\
\hline \multicolumn{5}{|l|}{ PT (sn) } \\
\hline Ribavirin & $0.92(0.50)$ & $-0.09 / 1.94$ & 3.586 & 0.062 \\
\hline Zaman (gün) & $-0.19(0.07)$ & $-0.33 /-0.06$ & 21.82 & $<0.001$ \\
\hline Ribavirin* zaman & $-0.02(0.09)$ & $-0.19 / 0.16$ & 0.035 & 0.850 \\
\hline \multicolumn{5}{|l|}{ aPTT (sn) } \\
\hline Ribavirin & $1.96(1.86)$ & $-1.74 / 5.67$ & 0.036 & 0.849 \\
\hline Zaman (gün) & $-1.68(0.19)$ & $-2.07 /-1.29$ & 204.40 & $<0.001$ \\
\hline Ribavirin* zaman & $-0.19(0.25)$ & $-0.70 / 0.31$ & 0.575 & 0.448 \\
\hline \multicolumn{5}{|l|}{ SSI } \\
\hline Ribavirin & $1.38(0.46)$ & $0.47 / 2.30$ & 1.983 & 0.163 \\
\hline Zaman (gün) & $-0.49(0.05)$ & $-0.58 /-0.40$ & 356.88 & $<0.001$ \\
\hline Ribavirin* zaman & $-0.16(0.06)$ & $-0.28 /-0.04$ & 6.83 & 0.009 \\
\hline
\end{tabular}

SE: Standart hata, GA: Güven aralığı, ALT: Alanin aminotransferaz, AST: Aspartat aminotransferaz; LDH: Laktat dehidrogenaz, PT: Protrombin zamanı, aPTT: Aktifleştirilmiş parsiyel tromboplastin zamanı SSI: Ciddiyet skor indeksi. 


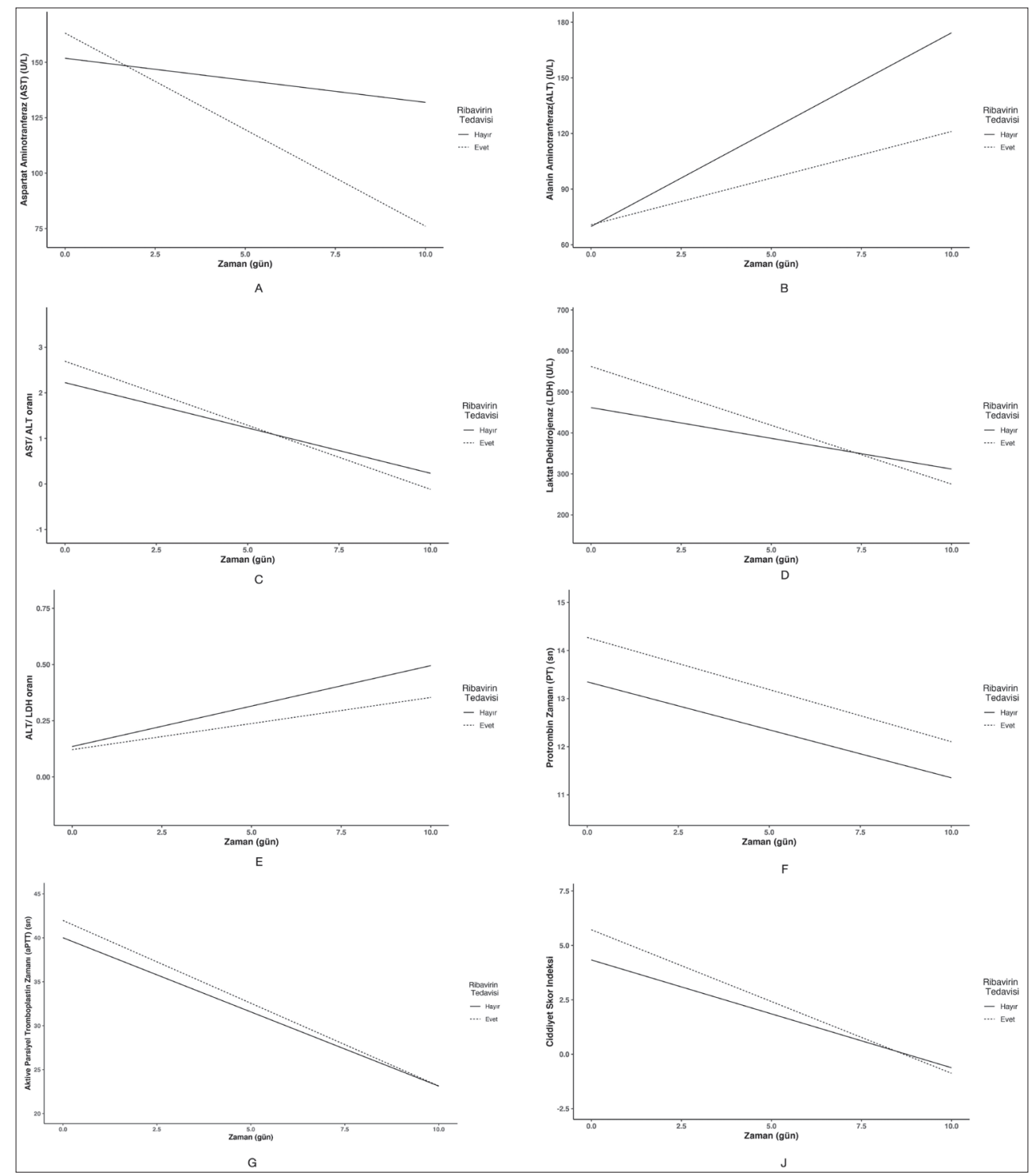

Şekil 2. Karaciğer enzimleri ve ciddiyet skor indeksi değerlerinin ribavirin-zaman etkileşim eğrileri.

\section{TARTIŞMA}

Kırım-Kongo kanamalı ateşi olan ve ribavirin tedavisi verilen 67 çocuk hastayla gerçekleştirilen bu çalışmanın ana bulguları, ribavirinin hemoglobin, WBC sayıları ve mutlak lenfosit sayılarını baskıladığını ancak ribavirin alan hastalarda karaciğer fonksiyon testleri ve şiddet skor indeksinin daha hızlı normalleştiğini göstermiştir.

KKKA'lı çocuklarda başlıca semptomlar ateş, kanama, kusma, halsizlik, baş ağrısı, miyalji, boğaz ağrısı, ishal ve makulopapüler döküntüdür ${ }^{14}$. Literatürdeki bulgulara benzer 
şekilde ateş, kusma, halsizlik, miyalji gibi temel bulgular daha sık görülürken, çalışmamızda ishal, mukozal kanama ve uyku hali daha az görülmüştür. Kene tutunmasından sonraki ortalama süre 5.5 gün olarak bulunmuştur ${ }^{15}$. Bu çalışmada her iki grupta da kuluçka süresinin daha kısa olduğu ve ölümcül olgunun olmadığı görülmüştür. Verilerimiz, çocuklarda ölüm oranının \%25 olarak bildirildiği İran'daki verilerle farklıık göstermektedir ${ }^{16}$. Türkiye'den yapılan başka bir çalışmada, hastalığa bağlı ölüm oranı \%5 olarak bildirilmiştir ${ }^{15}$. KKKA'lı hastalarda laboratuvar bulguları lökopeni, trombositopeni, AST, ALT, $\mathrm{LDH}$ ve CK artışı, PT ve aPTT sürelerinde uzama, fibrin yıkım ürünlerinde artış ve azalmış fibrinojen düzeyleridir ${ }^{17}$. Başvuru anında her iki grupta da lökopeni, trombositopeni, ALT, AST, LDH seviyelerinde yükselme, PT ve aPTT süresinde uzama bulunmuştur (Tablo II).

Bu çalışmada ribavirinin $\mathrm{Hb}$ düzeylerini düşürdüğü gözlemlenmiştir. Ribavirinin zamanla etkileşim etkisi anlamlı ve negatif bulunmuştur $(p<0.001$, Tablo III, Şekil 1-A). Ribavirinin kırmızı kan hücrelerinde ribavirin birikimine bağlı olarak hemolitik anemiye neden olduğu gösterilmiştir ${ }^{18}$. Bir çalışmada ribavirin uygulamasından hemen sonra hemoliz başladığı; doz $15 \mathrm{mg} / \mathrm{kg} / \mathrm{gün}$ 'ün üzerine çıkarıldığında hemoliz şiddetinin daha belirginleştiği ortaya konmuştur ${ }^{19}$. Hastalarımıza ilk gün $30 \mathrm{mg} / \mathrm{kg} / \mathrm{gün}$, sonraki 4 gün $15 \mathrm{mg} / \mathrm{kg} /$ gün ribavirin uygulanmıştır. Bu dozlar, akut hemoliz başlatmak için yeterince yüksektir. Hastalarımızda $\mathrm{Hb}$ azalmasının en tutarlı açıklaması ribavirinin hemoliz etkisidir.

Çalışmamızda düşük WBC sayısının klinik sonuçları gözlenmemiş olsa da lökopeni KKKA'da önemli bir endişe kaynağı olmuştur. Yüksek WBC seviyesi fatalite ile ilişkilendirilmiştir ${ }^{20}$. Çalışmamızda $10000 / \mathrm{mm}^{3}$ 'ün üzerinde bir WBC değeri yoktu. KKKA'da etkili bir tedaviden beklenti WBC düzeyinde hızlı bir artışa yol açmasıdır, böylece hastanın savunma mekanizmaları daha erken normalleşecektir ${ }^{10}$. Ribavirinin hem beyaz kan hücresi sayııını hem de mutlak lenfosit sayısını artışını baskıladığı bulunmuştur. Ribavirinin beyaz kan hücresi sayımı ve mutlak lenfosit sayımı ile etkileşim etkileri negatif olarak saptanmış, bu da ribavirinin hem WBC hem de mutlak lenfosit sayısının yükselmelerini geciktirdiğini göstermiştir ( $p<0.001$, Tablo III, Şekil I-B ve I-D). Bağışıklık sisteminin aşırı aktivasyonuna bağlı lenfosit tükenmesinin KKKA'de gösterilmesine ${ }^{21}$ ek olarak, ribavirinin lenfosit sayılarını de baskıladığı ${ }^{22}$ ve düşük dozlarda ribavirinin lenfosit fonksiyonlarını bozduğu, yüksek dozlarda lenfositler için sitotoksik olduğu gösterilmiştir ${ }^{23}$. Çalışmamızın bulguları literatürdeki çalışmaları desteklemektedir.

Karaciğer, KKKA'daki ana hedef organlardan biridir. KKKA'da artmış karaciğer hasarı belirteçleri bildirilmiştir ${ }^{14}$. Başvuru sırasında her iki grupta AST ve ALT aktivitelerinin benzer olduğu bulunmuştur (Tablo II). Bununla birlikte, zaman geçtikçe, ribavirinin ALT üzerine etkisi önemli ölçüde negatif hale gelmiştir ( $p<0.05$, Tablo IV ve Şekil 2-B). Sonuçlar, ribavirin alan hastalarda ALT yükselmesinin baskılandığını göstermiştir. AST düzeylerinde etkileşim anlamlı olmamakla birlikte, ribavirin verilen hastalarda daha hızlı düşürdüğü görülmüştür (Tablo IV, Şekil 2-A). Lassa ateşi üzerine yapılan bir araştırma; ribavirinin, enfekte olmuş hücreleri hücre ölümünden koruduğu, virüs bulaşını önlemediği fakat AST gibi hücre hasarı belirteçlerinin dolaşımını önemli ölçüde azalttığı bulunmuştur ${ }^{24}$. Çalışmamızdaki AST düzeyinde düşme ve ALT düzeyinin yükselme hızının baskılanması diğer 
viral enfeksiyonlar üzerindeki deneysel çalışmalara benzerliği, benzer mekanizmaların KKKA'da rol oynayabileceğini düşündürmüştür. Bulgularımızın aksine, bazı çalışmalarda ribavirinin karaciğer enzimleri üzerinde iyileştirici etkisi olmadığı bildirilmiştir ${ }^{25}$, ancak çaıısmamızın istatistiksel yöntemi farklıdır çünkü hastaların mevcut tüm tekrarlı verileri kullanılarak elde edilmiştir, böylece gözden kaçabilecek en küçük değişiklikler yakalanmıştır.

Laktat dehidrogenaz (LDH), anaerobik glikolizde rol oynayan ve vücudun her yerinde bulunan bir enzimdir ${ }^{26}$. LDH, influenza A virüsüne karşı antiviral ajanların aktivitesinin değerlendirilmesi için faydalı bir belirteç olarak önerilmiştir ${ }^{27}$. LDH yükselmesi hemen tüm KKKH olgularında gözlenmektedir ${ }^{2}$. Yüksek LDH seviyeleri akut karaciğer hasarı gibi hücrelerden sızıntının veya doku iskemisine bağlı artmış aktivitenin bir sonucu olarak görülmektedir ${ }^{26}$. Makrofajların aşırı aktivasyonunun KKKA'nın ilerlemesinde anahtar rol oynadığı gösterilmiştir ${ }^{28}$. Aşırı aktive edilmiş makrofajlar epitelyal hücre hasarına ve sinüzoidal fibrin birikimine neden olmaktadır ${ }^{29}$. Fibrin birikiminin mikrosirkülasyon tıkanıklığına yol açarak parankimal hipoksi ve nekroza neden olduğu gösterilmiştir ${ }^{29}$. KKKH'de ribavirinin LDH düzeylerini olumlu etkilediği gösterilebilirse ilacın etkin olduğu anlaşılacaktır. Çalışmamızda ribavirinin, hemoliz sonucunda LDH düzeylerinin hastalığın ilk evrelerinde arttığını gösteren pozitif fakat anlamlı olmayan başlıca bir etkiye neden olduğu bulunmuştur. Ancak, zaman geçtikçe etkinin tersine dönmüş ve negatifleşmiş olması ribavirinin LDH seviyelerini daha hızlı düşürdüğünü göstermiştir (Tablo IV ve Şekil II-D). Öte yandan LDH'nin yarı ömrü kısa olduğundan hızlı düşüş nedeninin karaciğer kaynakIı olup olmadığını anlamak için ALT/LDH oranına bakılması önerilmektedir ${ }^{26}$. ALT/LDH oranı, LDH yükselmesinin iskemiye mi yoksa başka nedenlere mi bağlı olduğunu teşhis etmek için tasarlanmıştır; sebat eden düşük ALT/LDH oranını karaciğer hasarının esas olarak iskemiden kaynaklandığı ileri sürülmüştür ${ }^{26}$. Çalışmamızda ALT/LDH oranının her iki grupta da hesaplanan değerin altında olması, LDH yükselmesinin ana kaynağının iskemi olduğunu düşündürmüştür. Öte yandan çalışmamızda zaman geçtikçe her iki grupta da oranın arttığı gözlenmiştir ancak ribavirin verilmeyen hastalarda oranın daha hızlı yükselme eğilimi olduğu gözlemlenmiştir. Bu durum, ribavirin verilmeyen hastalarda, karaciğer hasarının ilerleyen günlerde ön plana çıktığını göstermektedir.

KKKA'da pıhtılaşma testleri sıklıkla uzamıştır. Uzamış bir PT veya aPTT, prognostik bir faktör olarak kabul edilmektedir ${ }^{30}$. Çalışmamızda ribavirinin PT üzerindeki ana etkisi pozitif bulunmuş ve bu durum ribavirinin PT uzamasına neden olduğunu göstermiştir. Öte yandan, aPTT üzerindeki etkileşim etkisi önemli ölçüde negatif olmasına rağmen \%95 GA değerleri oldukça geniş bir aralıkta saptanmıştır, bu durum bulunan değerin ribavirinin aPTT düzeylerini düşürdüğü sonucuna varmak için yeterince kesin olmadığını göstermektedir. Ribavirinin pıhtılaşma faktörleri üzerinde etkisinin olmaması ve tersine PT'deki artış, ribavirinin karaciğerdeki hücre içi aktivitesinin yeterli olmadığı sonucuna ulaştırmıştır.

İlaç etkinliğini göstermek için yalnızca laboratuvar değerlerini bir vekil belirteç olarak araştırmak eksik sonuçlara yol açabilir, bu nedenle çalışmamızda, ciddiyet puanlamasın- 
daki günlük değişkenlikler de araştııılmışıı. KKKA'da şiddet skorlaması klinik ve laboratuvar verilerinin birlikte değerlendirilmesiyle elde edilmektedir ${ }^{11}$. Bu çalışmada, her hastanın takibinden günlük şiddet skorlaması yapılmışıı. Ribavirin ile tedavi edilen hastalarda ciddiyet skorunun daha hızı düştüğünü gösterilmiştir. Literatürde günlük şiddet puanlaması karşılaştırması ile ilgili herhangi bir yayın bulunamamışır. Bu anlamda çalışmamız, ilacın günlük ciddiyet puanlaması üzerindeki etkisini gösteren ilk yayın olmuştur.

Sonuç olarak ribavirin, KKKA'lı çocuk ve ergenlerde hastanede kalış süresini ve destekleyici tedavi sayısını azaltmamıştır. Ribavirinin başııca etkisi, bağışıkık modülasyonu yoluyla karaciğer fonksiyon testlerini ve şiddet puanlamasını iyileştirmesi olarak tespit edilmiştir.

\section{TEŞEKKÜR} riz.

Çalışmamızda yardımlarının esirgemeyen sayın Prof. Dr. Meryem Çetin'e teşekkür ede-

\section{ETIK KURUL ONAYI}

Bu çalışma, Gaziosmanpaşa Üniversitesi Tıp Fakültesi Girişimsel Olmayan Klinik Araştırmalar Etik Kurulu onayı ile gerçekleştirildi (Tarih: 31.12.2020 ve Karar No: 20-KAEK-306).

\section{ÇIKAR ÇATIŞMASI}

Yazarlar bu makale ile ilgili herhangi bir çıkar çatışması bildirmemişlerdir.

\section{KAYNAKLAR}

1. Bente DA, Forrester NL, Watts DM, McAuley AJ, Whitehouse CA, Bray M. Crimean-Congo hemorrhagic fever: history, epidemiology, pathogenesis, clinical syndrome and genetic diversity. Antiviral Res 2013; 100(1): 159-89.

2. Ergönül O. Crimean-Congo haemorrhagic fever. Lancet Infect Dis 2006; 6(4): 203-14.

3. Whitehouse CA. Crimean-Congo hemorrhagic fever. Antiviral Res 2004; 64(3): 145-60.

4. Tignor $\mathrm{GH}$, Hanham CA. Ribavirin efficacy in an in vivo model of Crimean-Congo hemorrhagic fever virus (CCHF) infection. Antiviral Res 1993; 22(4): 309-25.

5. Akinci $\mathrm{E}$, Yilmaz $\mathrm{M}$, Bodur $\mathrm{H}$ et al. Analysis of lymphocyte subgroups in Crimean-Congo hemorrhagic fever. Int J Infect Dis 2009; 13(5): 560-3.

6. Burt FJ, Leman PA, Smith JF, Swanepoel R. The use of a reverse transcription-polymerase chain reaction for the detection of viral nucleic acid in the diagnosis of Crimean-Congo haemorrhagic fever. J Virol Methods. 1998; 70(2): 129-37.

7. Yilmaz R, Kundak AA, Ozer S, Esmeray H. Successful treatment of severe Crimean-Congo hemorrhagic fever with supportive measures without ribavirin and hypothermia. J Clin Virol 2009; 44(2): 181-2.

8. Tasdelen Fisgin N, Ergonul O, Doganci L, Tulek N. The role of ribavirin in the therapy of Crimean-Congo hemorrhagic fever: early use is promising. Eur J Clin Microbiol Infect Dis 2009; 28(8): 929-33.

9. Borio L, Inglesby T, Peters C], et al. Hemorrhagic fever viruses as biological weapons: medical and public health management. JAMA 2002;287 (18): 2391-405.

10. Johnson S, Henschke N, Maayan N et al. Ribavirin for treating Crimean Congo haemorrhagic fever. Cochrane Database Syst Rev. 2018;6:CD012713. 
11. Dokuzoguz B, Celikbas AK, Gök ŞE, Baykam N, Eroglu MN, Ergönül Ö. Severity scoring index for CrimeanCongo hemorrhagic fever and the impact of ribavirin and corticosteroids on fatality. Clin Infect Dis 2013; 57(9): 1270-4.

12. Pinherio JC, Bates DM. Mixed-Effects Models in S and S-Plus. New York: Springer-Verlag New York Inc.; 2000

13. Shek DTL, Ma CMS. Longitudinal Data Analyses Using Linear Mixed Models in SPSS: Concepts, Procedures and Illustrations. ScientificWorldJournal. 2011; 11: 42-76.

14. Tezer H, Sucakli IA, Sayli TR et al. Crimean-Congo hemorrhagic fever in children. J Clin Virol 2010; 48(3): 184-6.

15. Dilber E, Cakir M, Acar EA et al. Crimean-Congo haemorrhagic fever among children in north-eastern Turkey. Ann Trop Paediatr 2009; 29(1) :23-8.

16. Keshtkar-Jahromi M, Sajadi MM, Ansari H, Mardani M, Holakouie-Naieni K. Crimean-Congo hemorrhagic fever in Iran. Antiviral Res 2013; 100(1): 20-8.

17. Ergönül O, Celikbaş A, Dokuzoguz B, Eren S, Baykam N, Esener H. Characteristics of patients with CrimeanCongo hemorrhagic fever in a recent outbreak in Turkey and impact of oral ribavirin therapy. Clin Infect Dis 2004; 39(2): 284-7.

18. Homma M, Matsuzaki $Y$, Inoue $Y$ et al. Marked elevation of erythrocyte ribavirin levels in interferon and ribavirin-induced anemia. Clin Gastroenterol Hepatol. 2004;2(4):337-339.

19. De Franceschi L, Fattovich G, Turrini F et al. Hemolytic anemia induced by ribavirin therapy in patients with chronic hepatitis C virus infection: role of membrane oxidative damage. Hepatology. 2000; 31(4): 9971004.

20. Swanepoel R, Gill DE, Shepherd AJ, Leman PA, Mynhardt JH, Harvey S. The Clinical Pathology of CrimeanCongo Hemorrhagic Fever. Rev Infect Dis 1989;11:S794-S800.

21. Bente DA, Alimonti JB, Shieh WJ et al. Pathogenesis and immune response of Crimean-Congo hemorrhagic fever virus in a STAT-1 knockout mouse model. J Virol 2010; 84(21): 11089-100.

22. Harrington PR, Fleischer R, Connelly SM, Lewis LL, Murray J. Ribavirin Reduces Absolute Lymphocyte Counts in Hepatitis C Virus-Infected Patients Treated With Interferon-Free, Direct-Acting Antiviral Regimens. Clin Infect Dis 2015; 61(6): 974-7.

23. Powers CN, Peavy DL, Knight V. Selective inhibition of functional lymphocyte subpopulations by ribavirin. Antimicrob Agents Chemother 1982; 22(1): 108-14.

24. Carrillo-Bustamante P, Nguyen THT, Oestereich L, Günther S, Guedj J, Graw F. Determining Ribavirin's mechanism of action against Lassa virus infection. Sci Rep 2017;7(1):11693.

25. Koksal I, Yilmaz G, Aksoy F et al. The efficacy of ribavirin in the treatment of Crimean-Congo hemorrhagic fever in Eastern Black Sea region in Turkey. J Clin Virol 2010; 47(1): 65-8.

26. Cassidy WM, Reynolds TB. Serum lactic dehydrogenase in the differential diagnosis of acute hepatocellular injury. J Clin Gastroenterol 1994; 19(2): 118-21.

27. Watanabe W, Sudo K, Asawa S, Konno K, Yokota T, Shigeta S. Use of lactate dehydrogenase to evaluate the anti-viral activity against influenza A virus. J Virol Methods 1995 ;51(2-3): 185-91.

28. Ergönül Ö, Şeref C, Eren Ş et al. Cytokine response in crimean-congo hemorrhagic fever virus infection. J Med Virol 2017; 89(10): 1707-13.

29. Tanaka M, Tanaka K, Masaki Y et al. Intrahepatic microcirculatory disorder, parenchymal hypoxia and NOX4 upregulation result in zonal differences in hepatocyte apoptosis following lipopolysaccharide- and D-galactosamine-induced acute liver failure in rats. Int J Mol Med 2014; 33(2): 254-62.

30. Cevik MA, Erbay A, Bodur $\mathrm{H}$ et al. Clinical and laboratory features of Crimean-Congo hemorrhagic fever: predictors of fatality. Int J Infect Dis 2008; 12(4): 374-9. 